\title{
Bi-level Hybrid Uncertainty Quantification in Fatigue Analysis: S-N Curve Approach
}

\author{
R. B. P. Nonato \\ Mechanical Engineering Department, Federal Center for Technological Education, CEFET/RJ, Nova Iguaçu, Brazil \\ raphaelbasili@@gmail.com, bttps://orcid.org/0000-0002-4740-9888
}

\begin{abstract}
Due to its physical complexity, fatigue phenomenon inherently presents a significant number of uncertain parameters to be predicted. In uncertainty quantification (UQ), research has demonstrated that even a small variation in uncertain input quantities (UIQs) may lead to a wide dispersion in the system response quantities (SRQs). In this paper, a bi-level hybrid UQ analysis of a fatigue problem is presented based on the $\mathrm{S}-\mathrm{N}$ curve approach. The uncertain fatigue analysis presented is able to deal simultaneously with aleatory- and epistemic-type uncertainties in two levels (a SRQ in the first level is a UIQ in the second level). To this end, the proposed scheme is tested for an AISI 4130 clamped beam subjected to a concentrated load, which material information comes from experiments reported in the literature. The UIQs are geometrical parameters, material properties, loading magnitude, and stress, while the SRQs are the stress (which is also a UIQ for fatigue life) and fatigue life. The results evidenced that the uncertain fatigue analysis, instead of providing a unique value for a $S R Q$, now produces a possible range of values. Therefore, depending on the risk an engineer can take on a design, there will be a corresponding level of optimization achieved.
\end{abstract}

KEYWORDS. Fatigue analysis; Uncertainty quantification; Uncertain fatigue analysis; S-N curve; Hybrid uncertainty quantification; Bi-level Hybrid uncertainty quantification.

\section{OPEN ACCESS}

Citation: Nonato, R.B.P., Bi-level Hybrid Uncertainty Quantification in Fatigue Analysis: S-N Curve Approach, Frattura ed Integrità Strutturale, 54 (2020) 88-103.

Received: 26.05 .2020

Accepted: 25.06.2020

Published: 01.10 .2020

Copyright: (C) 2020 This is an open access article under the terms of the CC-BY 4.0, which permits unrestricted use, distribution, and reproduction in any medium, provided the original author and source are credited.

\section{INTRODUCTION}

$\mathrm{U}$ nder the actual paradigm of industrial competition, the improvement of engineering design is an important issue in the usual quality-cost trade-off. In this context, uncertainty consideration in design intends to turn this process more realistic by measuring the impact of the quantities assumed as uncertain in the mechanical behavior of a structural system. Under fluctuating stresses, it has been estimated that the fatigue phenomenon contributes to the majority of service failures due to mechanical causes [1]. In this sense, although it is of great importance, the modeling of a fatigue phenomenon itself is a complex issue mainly due to the scarce experimental data available, which may lead to inadequate 
design assumptions. Therefore, inherently to the nature of this phenomenon, variability is present, for example, in the following parameters: geometry, material properties, loading, and environmental conditions [2-4]. Consequently, the integration of fatigue analysis with uncertainty quantification (UQ) intends to partially fulfill the gap of investigating the influence of each uncertain input quantity (UIQ) in the required system response quantities (SRQs) of a fatigue problem. From this perspective, the quantification mentioned may represent considerable knowledge for partially achieving the referred engineering design improvement, besides turning the analysis more complex $[2,5]$.

One of the greatest challenges presented in a fatigue analysis is to have the availability of the minimum required data in order to perform the most adequate analyses [1,6]. The scarcity or even the inexistence of this data leads the engineer to make assumptions and simplifications that may significantly affect the model accuracy. However, in possession of the minimum adequate information, the challenge relies on the modeling phase, key contributor for the accuracy of the responses obtained. Consequently, in the sense that UQ may diminish the technical gap between the conceptual model and the reality, UQ plays an important role in the accuracy of representation.

Therefore, aiming at qualifying a fatigue analysis to be more realistic, the integration with UQ deserves attention as a relevant topic of research. In this particular, three main approaches coexist: (a) probabilistic; (b) Bayesian inference; (c) probability bounds analysis (PBA). A considerable amount of research works is based on the so-called probabilistic methods, for example, [7-16]. The probabilistic approach is an adequate representation of an UIQ when there is sufficient random data to be representative of the distribution. In principle, the natural degree of data dispersion cannot be simply removed. However, this degree may be reduced by, e.g., improving the control of the generating process. Another branch of research within UQ in the context of fatigue analysis is the one related to Bayesian inference, as seen on [15,18]. Based on Bayes' theorem, more accurate inferences on SRQs may be reached by the available knowledge as the prior trustworthiness on model parameters.

Finally, the probability bounds analysis (PBA), which is applied in [3-4,19]. This type of analysis, on which this paper is structured, is fundamentally related to: (a) Monte Carlo sampling (MCS) or a variation of it; and (b) evidence theory [4]. PBA includes a mathematical characterization of aleatory uncertainties as probability distributions, and a characterization of epistemic uncertainties as interval-valued functions. If the two types of uncertainties are dependent on each other (which is not the case of this paper), the dependence should be assumed as an epistemic-type uncertainty [4]. However, under the segregation of aleatory- and epistemic-type of uncertainty throughout all UQ analysis, all assumed UIQs are mapped through the model and the SRQs are illustrated as bounds of probability distributions, known as p-boxes (set of all possible cumulative distribution functions - CDFs - contained within design boundaries).

Thenceforth, a general bi-level UQ analysis of a fatigue problem based on the S-N curve approach is introduced in this paper. The scheme presented here has the capability of treat aleatory- and epistemic-type uncertainties simultaneously in two levels (a SRQ in the first level is a UIQ in the second level). The UIQs were assumed to be the following: (a) geometrical parameters; (b) material properties, and magnitude of variable loading under cycles of constant amplitude, whereas the stress (which is also a UIQ for fatigue life in the second level) and fatigue life are the required SRQs. In order to test the proposed method, a clamped rectangular cross-section beam made of AISI 4130 subjected to a concentrated load is the object of study of the propagated uncertainties. Material properties were extracted from experimental data available in the literature. All the information was coded in $\mathrm{MATLAB}^{\circledR}$ in order to propagate the uncertainties (via MCS) throughout the mathematical model applied. The results are given in terms of the mean convergence studies of the SRQs, their probability density functions (PDFs), CDFs, coefficients of variation, correlation coefficients, and p-boxes. The sensitivity analyses (SAs) conducted evidenced that, under the conditions imposed herein, the greatest probabilistic contributor to the SRQ stress (first level) is the cross-section height of the beam. When the impact is verified on the SRQ fatigue life (second level), the height now turns to be the second most contributor, and the stress itself now is the most impacting factor in this fatigue design. Additionally, in order to also check the impact of the epistemic-type, the p-boxes are presented, segregating the two types of uncertainty in the same representation, aiming at showing the design boundaries for the loading condition of the problem studied. Therefore, under the consideration of uncertain parameters, a design point in the deterministic S-N curve turns to a lower and upper bounded set of design points, now obligating the designer to assume a certain risk when deciding to perform an analysis with fixed input parameters.

\section{DETERMINISTIC FATIGUE ANALYSIS: S-N CURVE APPROACH WITH CONSTANT AMPLITUDE LOADING}

$\mathrm{T}$ his section presents the deterministic fatigue design methodology under constant amplitude loading, its corresponding governing equations, assumptions, and particularities. A brief description of the deterministic S-N curve equation is given, in addition to the concept of damage. 


\section{Description of the S-N Approach}

For each design philosophy, there is at least one corresponding design methodology. In the fatigue context, the design methodology that conforms to a safe and infinite life is the stress-life approach, which the principal testing data description is the well-known S-N (Wöhler) curve. Although the method is recognized to be relatively simple and easy to apply, besides being able to give some initial perspective of the analysis, it is restricted to situations where continuum (absence of cracks) assumptions can be made. In addition, its range of application is reduced to the elastic range or near this limit, also addressing constant amplitude loading conditions.

A great number of researchers have devoted themselves to the process of S-N curve modeling, e.g., [1,6]. In order to build these curves, many tests in metallic materials in air at room temperature were performed, in which the independence between the number of cycles and the frequencies of the test could be verified. The fatigue life is also independent of the wave path that connects negative and positive stress peaks [6]. Therefore, the next subsection exposes the S-N approach under the mentioned conditions.

\section{Mathematical Background of the S-N Approach with Constant Amplitude Loading}

As far as this research could reach, there are three basic types of fatigue stress-life mathematical expressions, which have been studied by [20]. They are the following: (a) three-parameter stress-life model [21]; (b) Langer [22]; and (c) Basquin [23]. Presuming the existence of an infinite life, the latter model is the most common found in the literature and it is described by Eqn. (1), which represents the finite life portion adopted in this work and its limits.

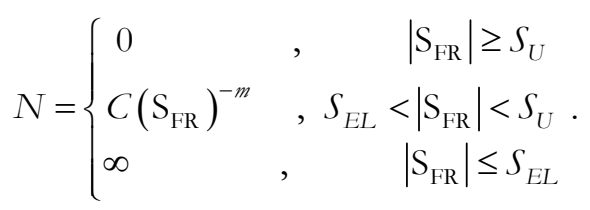

In Eqn. (1), $C$ and $m$ are constants corresponding to the material tested, $S_{\mathrm{FR}}$ is the fatigue limit in fully reversed loading condition, $\mathrm{S}_{\mathrm{EL}}$ is the endurance limit (threshold between finite and infinite life), $\mathrm{S}_{\mathrm{U}}$ is the ultimate stress (rupture limit) and $\mathrm{N}$ is the fatigue life (in number of cycles). If the actuating stress $\mathrm{S}_{\mathrm{FR}}$ is greater than the rupture limit, the component will fail; and if $\mathrm{S}_{\mathrm{FR}}$ is lower than the endurance limit of this component, it will present an infinite life. Simply taking the logarithm on both sides of Eqn. (1) correspondent to the finite life, a straight-line representation results in Eqn. (2):

$$
\log (N)=\log (C)-m \log \left(\mathrm{S}_{\mathrm{FR}}\right)
$$

$\mathrm{S}_{\mathrm{FR}}$ is selected particularly in this formulation because fatigue data is mostly obtained in the fully reversed loading condition. The non-linear model adopted is the classical Gerber expression [1] because it is the least conservative when compared to Soderberg and Goodman, for example. Therefore, the fatigue limit in fully reversed loading condition can be written in accordance with Eqn. (3):

$$
S_{F R}=\frac{S_{A}}{1-\left(\frac{S_{M}}{S_{U}}\right)^{2}},
$$

where $S_{A}$ is the cyclic stress amplitude and $S_{M}$ is the mean stress. In the case of constant amplitude loading, $S_{A}$ and $S_{M}$ may be obtained in terms of the minimum and maximum stresses, $S_{\text {MIN }}$ and $S_{\text {MAX }}$, respectively, by Eqns. (4) and (5):

$$
\begin{aligned}
& S_{A}=\frac{S_{M A X}-S_{M I N}}{2} ; \\
& S_{M}=\frac{S_{M A X}+S_{M I N}}{2} .
\end{aligned}
$$


For the condition of fully reversed stress amplitude, Eqns. (4) and (5) yield Eqns. (6) and (7):

$$
\begin{aligned}
& S_{A}=S_{M A X} ; \\
& S_{M}=0 .
\end{aligned}
$$

Substituting Eqns. (3), (6), and (7) into Eqn. (1), an equation of fatigue life as a function of materials properties and maximum stress turns into Eqn. (8):

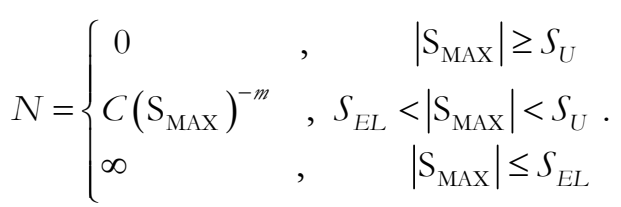

To estimate when a component will fail, the fatigue process is based on the assumption of damage accumulation paradigm, which does not consider the effects of understressing and overstressing. The specimen with finite life resists until the life of the component is exhausted. Under the stress range corresponding to infinite life, theoretically, the part never reaches the exhaustion. The cumulative damage during this process is frequently obtained by applying the Palmgren-Miner linear cumulative damage rule, which has several limitations referred to its applicability conditions, but it is simple and fast to implement. This rule states that the fatigue life of a component can be predicted by adding up the part of the life correspondent to each stress level. Mathematically, the cumulative fatigue damage D is represented in Eqn. (9):

$$
D=\sum_{i=1}^{j} D_{i}
$$

where $\mathrm{D}_{\mathrm{i}}$ is understood as the damage corresponding to the $\mathrm{i}$-th stress level. In this particular, now representing $\mathrm{S}_{\mathrm{MAX}}$ as simply $S_{i}$, the fractional damage $D_{i}$ is given by Eqn. (10):

$$
D_{i}=\left\{\begin{array}{lll}
\infty & , & \left|\mathrm{S}_{\mathrm{i}}\right| \geq S_{U} \\
\frac{1}{C} \mathrm{n}_{\mathrm{i}} \mathrm{S}_{\mathrm{i}}^{\mathrm{m}} & , & S_{E L}<\left|\mathrm{S}_{\mathrm{i}}\right|<S_{U}, \\
0 & , & \left|\mathrm{~S}_{\mathrm{i}}\right| \leq S_{E L}
\end{array}\right.
$$

where $n_{i}$ is the number of cycles performed at the $\mathrm{i}$-th stress level $S_{i}$ and $N_{i}$ is the fatigue life (in number of cycles) at $S_{i}$ considering the fully reversed amplitude loading condition. Therefore, when $\mathrm{D}=1$, theoretically, the component fails by fatigue [24].

\section{UNCERTAIN FATIGUE ANALYSIS: S-N CURVE APPROACH}

$\mathrm{T}$ his section presents some generic sources and a basic classification of uncertainties. It also describes the methodology to treat aleatory- and epistemic-type uncertainties in a fatigue problem under the stress-life method of solution. Mathematical models for the stress as a function of geometrical parameters and applied loads (first level) and for the number of cycles as a function of applied loads, geometrical parameters, and material properties (second level) are also presented.

\section{Sources of Uncertainty and Classification}

Some of the sources of uncertainty present in real engineering applications occur due to manufacturing, material variability, initial conditions, system wear or damaged condition and its surroundings. Information on magnitude, type, behavior, and sources of uncertainty is crucial in the decision-making process for engineered systems. The main sources of uncertainty can be listed as: (a) model inputs (data from surroundings and model); (b) numerical approximation (when solving discrete 
equations, instead of differential, for example); and (c) model form (assumptions, simplifications, mathematical formulations, etc.) [4]. In the field of model-based predictions, uncertainty originates from model inputs (boundary conditions, initial conditions, etc.), gap between real system and adopted model, computational costs (time to accomplish the run, analysis feasibility, and complexity), solution, and errors [25].

There are several classifications related to uncertainties, which mainly diverge in the nomenclature adopted but rarely related to the concept, for example, $[4,26]$. The selected terminology of the types of uncertain parameters employed here are described in [4]. According to this reference, they can be listed as: (a) aleatory: commonly represented by a PDF and/or cumulative density function (CDF). The modeled system has intrinsic variability, such that it is inherent to the phenomenology of the problem. This type of uncertainty cannot be eliminated, even if the available information is the most reliable, but can be better quantified in order to be reduced; (b) epistemic: represented by an interval variable, it occurs when there is a lack of complete information or knowledge. If more information is added into the analysis, it can be reduced; (c) mixed: it is simply a combination of the previous two, and, therefore, can be characterized by a PDF or a CDF with an interval. For example, if the sample size is small compared to the population, the PDF or CDF characterization related to the random variable is impaired in its accuracy. In this case, the uncertainty is defined as a combination of aleatory- and epistemic-type.

\section{Aleatory-type Uncertainty}

In the case of aleatory-type uncertainty, the information comes from a selected, candidate, or available probability distribution. Let $n_{k}$ be the number of known parameters of the probability distribution function of the $\mathrm{i}$-th probabilistic UIQ $X_{i}$. If the PDF of $X_{i}$ is denoted by $f_{X_{i}}\left(x_{i}, k, \ldots, n_{k}\right)$, then the realizations of $X_{i}$ are obtained by the inverse function of the PDF (Eqn. (11)):

$$
x_{i}=f_{X_{i}}^{-1}\left(x_{i}, k, \ldots, n_{k}\right) \text {, }
$$

where $\mathrm{x}_{\mathrm{i}}$ is a possible outcome of a universal set $\chi_{\mathrm{i}}$ of all possible outcomes and $\mathrm{k}$ is the $\mathrm{k}$-th known parameter. A cumulative distribution function (CDF) $\mathrm{F}_{\mathrm{Xi}}$ can be assigned to every element $\mathrm{x}_{\mathrm{i}}$ such that the following conditions are satisfied (Eqns. (12) and (13)):

$$
\begin{aligned}
& F_{X_{i}}\left(x_{i}, k, \ldots, n_{k}\right) \in[0,1], \forall x_{i} \in \chi_{i} ; \\
& \sum_{x_{i} \in \chi_{i}} F_{X_{i}}\left(x_{i}, k, \ldots, n_{k}\right)=1 .
\end{aligned}
$$

\section{Epistemic-type Uncertainty}

Originated by the interval analysis [27], the epistemic model of uncertainty is implemented in a UQ process in which there is no sufficient knowledge about the behavior of a variable. It is a non-probabilistic method to represent and propagate epistemic-type of uncertainties in engineering problems. Any realization within the interval represents only a possibility without a probability associated. Therefore, it can be simply described by the $j$-th UIQ as an interval variable (Eqn. (14)):

$$
Y_{j}=\left[Y_{j}^{L B}, Y_{j}^{U B}\right] \in \mathbb{R}^{I}
$$

in which $\mathbb{R}^{\mathrm{I}}$ is the set of all closed real interval numbers, $\mathrm{Y}_{j}^{\mathrm{LB}}$ and $\mathrm{Y}_{j}^{\mathrm{UB}}$ are the lower and upper bounds of the $j$-th epistemic UIQ, respectively. The governing theory characterizes an interval variable by two basic parameters: the mean or central value and the amplitude, respectively, given by Eqs (15) and (16):

$$
\begin{aligned}
& Y_{j}^{M}=\frac{1}{2}\left(Y_{j}^{L B}+Y_{j}^{U B}\right) ; \\
& \Delta Y_{j}=\frac{1}{2}\left(Y_{j}^{U B}-Y_{j}^{L B}\right) .
\end{aligned}
$$


Bi-level Hybrid Uncertain S-N Curve Approach

A UQ process comprises the obtainment of uncertainties correspondent to model-based predictions [4], which can be based on the different types of uncertainty throughout calculation levels. The bi-level hybrid approach adopted in this paper can deal with aleatory- and epistemic-type uncertainties simultaneously, but in a segregated manner in two distinct levels. The SRQ obtained in the first level turns out to be the UIQ in the second level of propagation, i.e. the SRQ calculated in the second level is influenced by the UIQs of the same level and by the SRQ of the previous level. Values of the SRQs are obtained as a result of the mapping of the UIQs throughout the uncertainty propagation process. In order to accomplish this task some propagation methods were proposed [28-33]. In view of these, Monte Carlo simulation (MCS) is the method through which the uncertainties are propagated in this work. Although it requires a larger sample size, the example solved herein shows that the convergence is achieved without a reasonable computational effort, which partially justifies the application of the MCS. The ease of implementation also explains its selection. In a generic form, Eqn. (17) is presented as the model structure responsible for mapping the required SRQs in terms of the types of uncertainties:

$$
\mathbb{M}\left(\mathbf{X}_{1}, \mathbf{X}_{2}, \ldots, \mathbf{X}_{i}, \ldots, \mathbf{X}_{n_{i}}, \mathbf{Y}_{1}, \mathbf{Y}_{2}, \ldots, \mathbf{Y}_{j}, \ldots, \mathbf{Y}_{n_{j}}\right) \rightarrow \mathbf{Z}_{1}, \mathbf{Z}_{2}, \ldots, \mathbf{Z}_{k}, \ldots, \mathbf{Z}_{n_{k}}
$$

in which $n_{i}$ is the number of column vectors of aleatory-type UIQs, $n_{j}$ is the number of column vectors of epistemic-type UIQs, and $n_{k}$ is the number of column vectors of SRQs required in the UQ analysis. Under the conditions of the adopted mathematical model $\mathbb{M}$, the mapping of the dependence of the output uncertain data on the input uncertain data is performed. The named process (propagation of uncertainties) is fundamentally dedicated to obtain the effect of the set of the $n_{i}$ vectors and the $n_{j}$ vectors on the $n_{k}$ vectors. Therefore, the column vectors corresponding to each type of parameter are represented by the following structure (Eqn. (18)):

$$
\begin{aligned}
& \mathbf{X}_{i}=\left[x_{i}^{(1)}, x_{i}^{(2)}, \ldots, x_{i}^{(p)}, \ldots, x_{i}^{\left(n_{r}-1\right)}, x_{i}^{\left(n_{r}\right)}\right]^{T} \\
& \mathbf{Y}_{j}=\left[y_{j}^{(1)}, y_{j}^{(2)}, \ldots, y_{j}^{(q)}, \ldots, \mathrm{y}_{j}^{\left(n_{r}-1\right)}, \mathrm{y}_{j}^{\left(n_{r}\right)}\right]^{T} \\
& \mathbf{Z}_{k}=\left[\mathrm{z}_{k}^{(1)}, \mathrm{z}_{k}^{(2)}, \ldots, \mathrm{z}_{k}^{(r)}, \ldots, \mathrm{z}_{k}^{\left(n_{r}-1\right)}, \mathrm{z}_{k}^{\left(n_{r}\right)}\right]^{T},
\end{aligned}
$$

where the superscript of each element of each vector refers to the realization number. Since just one SRQ can be obtained from each mathematical expression (one level), the $r$-th realization of the k-th SRQ should be obtained by solving the corresponding equation with the $\mathrm{p}$-th realization of all the needed aleatory-type UIQs in conjunction with the q-th realization of all the needed epistemic-type UIQs. This is true if, and only if, $\mathrm{p}=\mathrm{q}=\mathrm{r}, \forall 1 \leq \mathrm{p}, \mathrm{q}, \mathrm{r} \leq \mathrm{n}_{\mathrm{r}}$. Performing these calculations for all the $n_{k}$ SRQs, a number of $n_{k} x n_{r}$ values (elements) are obtained to compose the responses of whole model. According to the deterministic S-N curve approach presented, i.e. assuming the condition of fully reversed constant amplitude loading, the general Basquin mathematical model, represented by Eqn. (1), was particularized into the Eqn. (8). Regarding only its finite domain, Eqn. (19) states the second level as a function of the SRQ $S_{\text {MAX }}$ (from the first level) and the UIQs C and $\mathrm{m}$ (from the second level) (Eqn. (19):

$$
\mathbf{N}=f\left(\mathbf{S}_{M A X}, \mathbf{C}, \mathbf{m}\right) \quad, \quad \mathrm{S}_{\mathrm{EL}}^{(\mathrm{p})}<\left|S_{M A X}^{(p)}\right|<S_{U}^{(p)}, \quad \forall p \in \mathbb{R} \mid 1 \leq p \leq n_{r} .
$$

For the purposes of the second level UQ analysis, the independent variable column vectors, $\mathbf{C}, \mathbf{S}_{\mathrm{MAX}}$, and $\mathbf{m}$, may constitute a set of one, two, or three UIQs, whereas the dependent variable column vector $\mathbf{N}$ is the SRQ. If a parameter is known exactly, then it can be assumed as deterministic in this process (not a UIQ). Among other factors, the quantity of nondeterministic parameters in an analysis is defined by the focus of the study and limitations of computational capacity.

Analogously to the model of Eqn. (17), the column vector $\mathbf{S}_{\mathrm{MAx}}$ (now an SRQ in the first level) can be expressed as a function of $n_{s}$ vectors of applied loads and $n_{t}$ vectors of geometrical parameters involved, as can be seen in Eqn. (20). $F_{s}$ is the column vector of the s-th applied force and $\mathbf{G}_{\mathrm{t}}$ is the column vector of the $\mathrm{t}$-th geometrical parameter considered.

$$
\mathbf{S}_{M A X}=f\left(\mathbf{F}_{1}, \mathbf{F}_{2}, \ldots, \mathbf{F}_{s}, \ldots, \mathbf{F}_{n_{s}}, \mathbf{G}_{1}, \mathbf{G}_{2}, \ldots, \mathbf{G}_{t}, \ldots, \mathbf{G}_{n_{t}}\right), \mathrm{S}_{\mathrm{EL}}^{(\mathrm{p})}<\left|S_{M A X}^{(p)}\right|<S_{U}^{(p)}, \forall p \in \mathbb{R} \mid 1 \leq p \leq n_{r}
$$


Thenceforth, combining Eqns. (17) and (20), the mathematical model wherewith the propagation of all UIQs is performed is given by Eqn. (21), where $\mathbf{M}_{\mathrm{u}}$ is the vector of the $\mathrm{u}$-th material property and $\mathrm{n}_{\mathrm{u}}$ is the number of vectors of material properties involved. Since $\mathbf{S}_{\mathrm{MAX}}$ is implicit in Eqn. (21), this expression corresponds to the bi-level hybrid UQ model already mentioned.

$$
\mathbf{N}=f\left(\mathbf{F}_{1}, \mathbf{F}_{2}, \ldots, \mathbf{F}_{s}, \ldots, \mathbf{F}_{\mathrm{n}_{\mathrm{s}}}, \mathbf{G}_{1}, \mathbf{G}_{2}, \ldots, \mathbf{G}_{t}, \ldots, \mathbf{G}_{\mathrm{n}_{\mathrm{t}}}, \mathbf{M}_{1}, \mathbf{M}_{2}, \ldots, \mathbf{M}_{u}, \ldots, \mathbf{M}_{n_{u}}\right)
$$

Therefore, Eqns. (20) and (21) are applied to the uncertain fatigue problem to be solved (uncertain S-N curve approach with all the assumptions made) and is calculated for each realization of each UIQ, obtaining the correspondent value for the same realization of the required SRQ.

\section{Numerical EXample: CANTILEVER BEAM With ConCENTRATEd LoAD}

7 he numerical example treated herein consists of a clamped beam subjected to a concentrated load near its free end, in which its UIQs were identified and characterized. A bi-level hybrid UQ analysis was conducted to investigate the behavior of the required SRQs in the two levels followed by a sensitivity analysis (SA) to rank the UIQs, disposing them in decreasing order of impact on the variability of the SRQs.

\section{Basic Description of the Problem}

To illustrate the problem to be solved in the context of a UQ analysis, Fig. 1 is now introduced. The beam made of AISI 4130 is clamped at its left end, whereas its right end is free to displace. A concentrated variable load with constant amplitude has magnitude $\mathrm{F}$ and is pointed downward the $\mathrm{y}$-axis near the free end, thus producing a downward deflection. However, because it is fully reversed, an upward deflection is produced when the load direction is upward. The prismatic beam is characterized geometrically by its length $\mathrm{L}$ (parallel to $\mathrm{x}$-axis), cross-section base $\mathrm{b}$ (parallel to $\mathrm{z}$-axis), cross-section height $\mathrm{h}$ (parallel to y-axis), and the longitudinal distance $\mathrm{d}$ (parallel to $\mathrm{x}$-axis) between the structural support and the load application point (taken orthogonally to the upper clamped edge of the beam). Its material properties are the parameters related to fatigue $\left(\mathrm{C}, \mathrm{m}\right.$, and $\left.\mathrm{S}_{\mathrm{EL}}\right)$, and $\mathrm{S}_{\mathrm{U}}$. It is important to observe that the deflection magnitude is not a design restriction (serviceability requirement) in this work and that the body forces are neglected for simplification purposes.

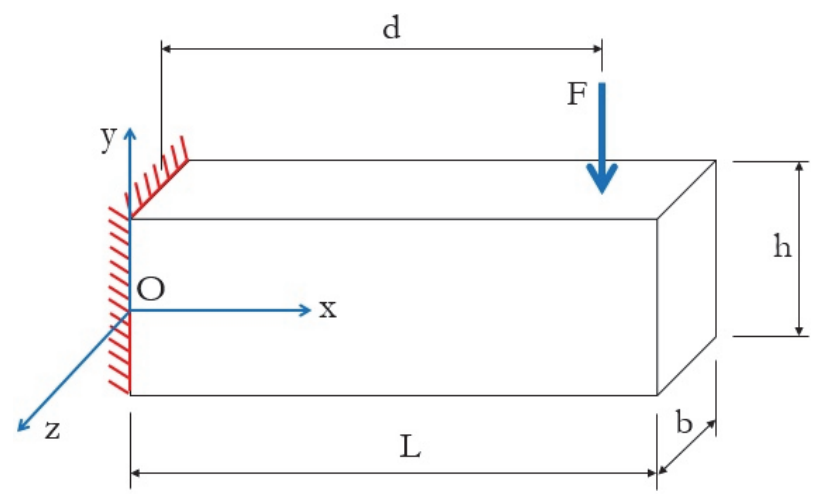

Figure 1: Cantilever beam subjected to a concentrated variable load with constant amplitude F near its free end with the nomenclature of geometrical parameters.

The UIQs and SRQs considered in this analysis are organized in Tab. 1, which also contains the characterization of each input quantity, and the values of the parameters needed to calculate the behavior of the UIQs and SRQs. The specific values of $C$ and $m$ were extracted from an interpolated equation based on experimental data points collected from [34], in which the material selected corresponds to unnotched specimens which ultimate stress is approximately $806.687 \mathrm{MPa}$. This interpolated equation (Eqn. (22)) is valid only for the stress ratio $\mathrm{R}=-1$ (Eqn. (22)). Thenceforth, rearranging for the SRQ N, Eqn. (23) is obtained:

$$
\log (N)=9.27-3.57 \log \left(S_{M A X}-43.3\right)=\log (C)-m \log \left(S_{\text {MAX }}-43.3\right)
$$




$$
N=C\left(S_{M A X}-43.3\right)^{-m}
$$

where $\mathrm{S}_{\mathrm{MAX}}$ is given in ksi and $\mathrm{C}$ is in $(\mathrm{ksi})^{\mathrm{m}}$. In order to work with units of système internationale (SI), where $\mathrm{S}_{\mathrm{MAX}}$ is now given in $\mathrm{MPa}$ and $\mathrm{C}$ is in $(\mathrm{MPa})^{\mathrm{m}}$, the converted form of Eqn. (23) yields Eqn. (24):

$$
N=6.895^{m} C\left(S_{\text {MAX }}-298.543\right)^{-m}
$$

where the maximum stress for this problem is obtained by Eqn. (25):

$$
S_{M A X}=6 \frac{F d}{b h^{2}} .
$$

\begin{tabular}{|c|c|c|c|c|c|}
\hline UIQ & SRQ & $\begin{array}{l}\text { Deterministic } \\
\text { Value of UIQ }\end{array}$ & $\begin{array}{l}\text { Type of } \\
\text { uncertainty }\end{array}$ & $\begin{array}{l}\text { Mathematical } \\
\text { representation }\end{array}$ & Parameters \\
\hline $\mathrm{b}$ & $\mathrm{S}_{\mathrm{MAX}}, \mathrm{N}$ & $\mathrm{b}^{\mathrm{D}}=33.60 \mathrm{~mm}$ & Aleatory & Gaussian & $\mu_{\mathrm{b}}=33.60 \mathrm{~mm} ; \sigma_{\mathrm{b}}=0.084 \mathrm{~mm}$ \\
\hline $\mathrm{h}$ & $\mathrm{S}_{\mathrm{MAX}}, \mathrm{N}$ & $\mathrm{h}^{\mathrm{D}}=60.48 \mathrm{~mm}$ & Aleatory & Uniform & $\mu_{\mathrm{h}}=60.48 \mathrm{~mm} ; \mathrm{h}^{\mathrm{LB}}=60.17 \mathrm{~mm} ; \mathrm{h}^{\mathrm{UB}}=60.79 \mathrm{~mm}$ \\
\hline $\mathrm{F}$ & $\mathrm{S}_{\mathrm{MAX}}, \mathrm{N}$ & $\mathrm{FD}=6000 \mathrm{~N}$ & Aleatory & Weibull & $\alpha=6000 \mathrm{~N} ; \beta=3 \times 10^{-4}$ \\
\hline $\mathrm{d}$ & $\mathrm{S}_{\mathrm{MAX}}, \mathrm{N}$ & $\mathrm{d}^{\mathrm{D}}=2000 \mathrm{~mm}$ & Epistemic & Interval & $\mathrm{d}^{\mathrm{M}}=2000 \mathrm{~mm} ; \mathrm{d}^{\mathrm{LB}}=1990 \mathrm{~mm} ; \mathrm{d}^{\mathrm{UB}}=2010 \mathrm{~mm}$ \\
\hline C & $\mathrm{N}$ & $\mathrm{CD}^{\mathrm{D}}=10^{9.27}(\mathrm{MPa})^{\mathrm{m}}$ & Epistemic & Interval & $\begin{array}{c}\mathrm{C}^{\mathrm{M}}=10^{9.27}(\mathrm{MPa})^{\mathrm{m}} ; \mathrm{C}^{\mathrm{LB}}=1.852777 \times 10^{9}(\mathrm{MPa})^{\mathrm{m}} ; \\
\mathrm{C}^{\mathrm{UB}}=1.871398 \times 10^{9}(\mathrm{MPa})^{\mathrm{m}}\end{array}$ \\
\hline $\mathrm{m}$ & $\mathrm{N}$ & $\mathrm{m}^{\mathrm{D}}=3.570$ & Epistemic & Interval & $\mathrm{m}^{\mathrm{M}}=3.57 ; \mathrm{m}^{\mathrm{LB}}=3.552 ; \mathrm{m}^{\mathrm{UB}}=3.588$ \\
\hline $\mathrm{S}_{\mathrm{MAX}}$ & $\mathrm{N}$ & $\mathrm{S}_{\mathrm{MAX}} \mathrm{D}=585.8 \mathrm{MPa}$ & $\begin{array}{c}\text { Not } \\
\text { applicable }\end{array}$ & $\begin{array}{c}\text { Not } \\
\text { applicable }\end{array}$ & Not applicable \\
\hline
\end{tabular}

Table 1: Detailing of the UIQs and SRQs of the cantilever beam example.

In Tab. $1, \mu$ is the mean, $\sigma$ is the standard deviation, $\alpha$ is the shape parameter, and $\beta$ is the scale parameter. The superscripts $\mathrm{M}, \mathrm{LB}$, and UB stand for mean, lower bound, and upper bound of the indicated interval, respectively. The type of uncertainty, its mathematical representation, and its parameters are not applicable for $\mathrm{S}_{\mathrm{MAX}}$ as a UIQ (condition of the second level) because $\mathrm{S}_{\mathrm{MAX}}$ is a consequence of the first level, thus not being a direct input for $\mathrm{N}$. All the parameters contained in Tab. 1 refer to the load condition of closest proximity to the maximum stress and minimum number of cycles of the finite part of the S-N curve modeled by Eqn. (21). The study of the behavior of the structure at high stresses was made in order to show the variability of the fatigue life in the condition where it presents its lowest value. In this situation, a fixed coefficient of variation in fatigue life would be more representative. However, this makes sense especially when dealing with structural systems which loading is of low frequency. In other words, this loading condition corresponds to the maximum applied load $\mathrm{F}=6000 \mathrm{~N}$, which corresponds to the stress $\mathrm{S}=585.8 \mathrm{MPa}$. It can also be noted from Tab. 1 that the deterministic values are used as information for the UIQs: (a) for the aleatory-type of uncertainty, the deterministic value of each UIQ is assumed as the mean of the adopted distribution; (b) in the case of epistemic-type, the deterministic value is attributed to the central value of the corresponding interval. It is important to observe that since body forces were neglected, the only condition that length $\mathrm{L}$ has to comply with is that $\mathrm{L} \geq \mathrm{d}^{\mathrm{UB}}$. Therefore, $\mathrm{L}$ can be equal to $2020 \mathrm{~mm}$ (deterministic) for the purposes of this analysis.

The particularization of the Eqn. (17) for the problem just described is shown in Eqn. (26), which consists of the bi-level model. Consequently, $\mathrm{n}_{\mathrm{i}}=3(\mathbf{b}, \mathbf{h}$, and $\mathbf{F}), \mathrm{n}_{\mathrm{j}}=3(\mathbf{d}, \mathbf{C}$, and $\mathbf{m})$, and $\mathrm{n}_{\mathrm{k}}=2\left(\mathbf{S}_{\mathrm{MAX}}\right.$ and $\left.\mathbf{N}\right)$.

$$
\mathbb{M}(\mathbf{b}, \mathbf{h}, \mathbf{F}, \mathbf{d}, \mathbf{C}, \mathbf{m}) \rightarrow \mathbf{S}_{M A X}, \mathbf{N}
$$

Analogously, Eqns. (20) and (21) adapted to the proposed problem, yields Eqns. (27) and (28), respectively.

$$
\mathbf{S}_{M A X}=f(\mathbf{F}, \mathbf{b}, \mathbf{h}, \mathbf{d}) .
$$




$$
\mathbf{N}=f(\mathbf{F}, \mathbf{b}, \mathbf{h}, \mathbf{d}, \mathbf{C}, \mathbf{m}) \text {. }
$$

In accordance with Eqns. (27) and (28), all the calculation and generation of graphical results were performed in MATLAB ${ }^{\circledR}$ 2016. The MCS coded in this software was implemented using a different seed random number for each sample generated (pseudo-random number generation). Next section is dedicated to show the results of these simulations, besides some comments about them.

\section{Results and Comments}

The PDFs of the aleatory-type UIQs for the mentioned load case are pictured in Fig. 2. Cross-section basis b, cross-section height $\mathrm{h}$ (both in $\mathrm{mm}$ ), and applied load $\mathrm{F}$ (in $\mathrm{N}$ ) are represented by blue continuous lines according to 5000 realizations of their correspondent distributions (characterization of uncertainties in Tab. 1). Vertical continuous red lines correspond to their deterministic values, represented by the letter D. Fig. 3 shows their CDFs and also the related deterministic values. The variation profile of the epistemic-type uncertainty is represented by an interval between the lower and upper bounds with the possible values between them (without a probability associated to each one), reason why their graphical representation will not be made here.
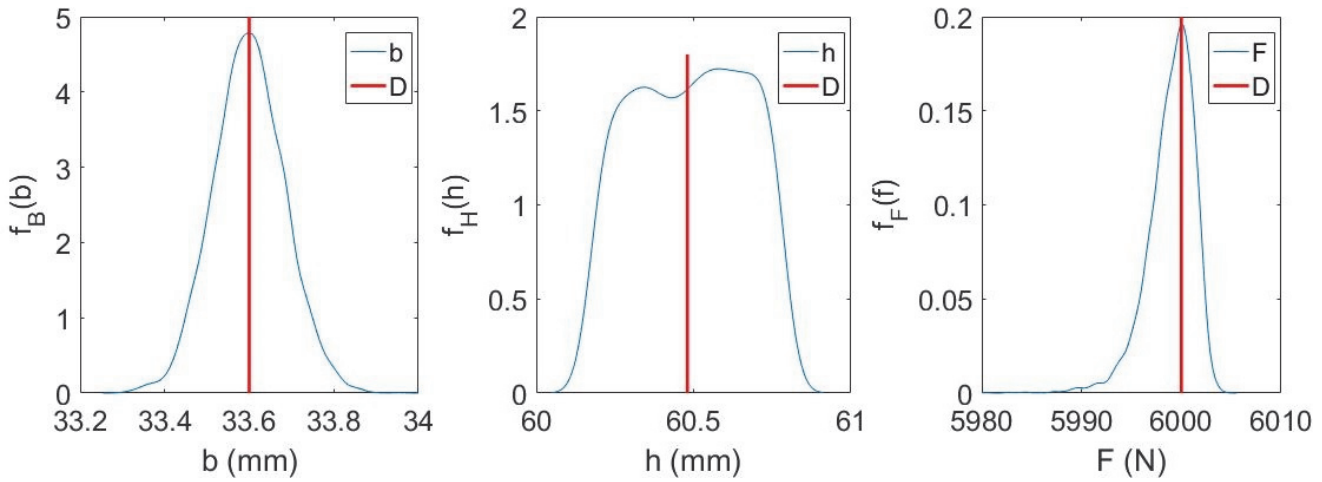

Figure 2: PDFs of the aleatory-type UIQs and their deterministic values.
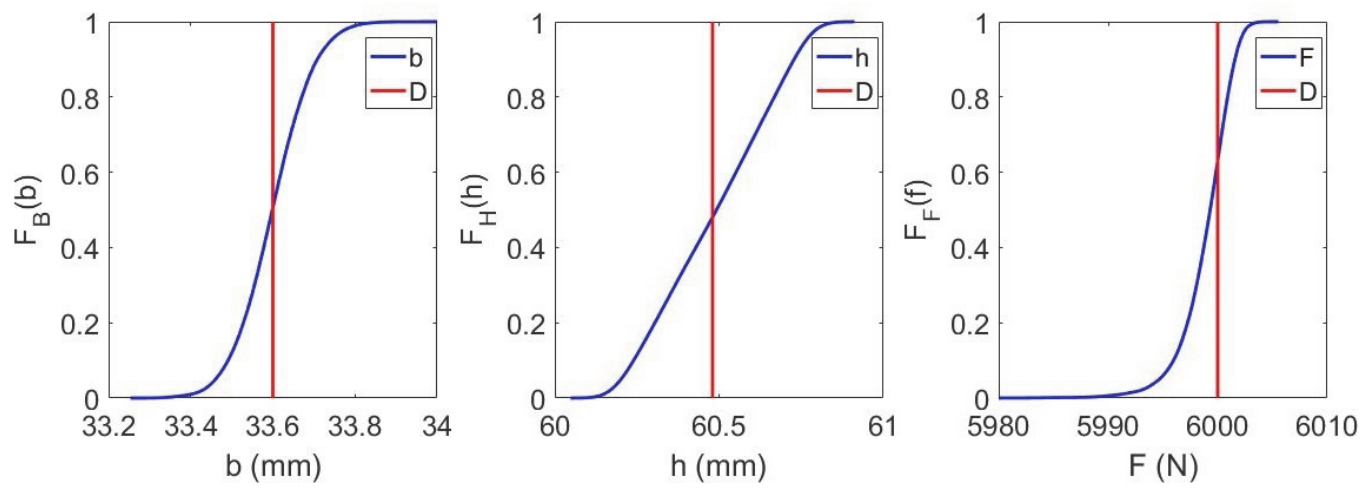

Figure 3: CDFs of the aleatory-type UIQs and their corresponding deterministic values.

Fig. 4 and Fig. 5 illustrate the PDFs and CDFs of the SRQs of this problem, respectively. Some statistical parameters of the UIQs and SRQs shown in these figures are presented in Tabs. 2 and 3. The estimated values indicated by the columns of these tables are those obtained from the simulations in the code developed. The relative errors between the deterministic values (Tabs. 2 and 3) and the obtained means (Tab. 2) are shown in the penultimate column of Tab. 3. The good agreement between the deterministic and the means of the SRQs is partially explained by the assumption of a considerable degree of symmetry verified in the distributions of the aleatory UIQs. Particularly for epistemic-type, it is conceptually understood as symmetrically disposed. In the case of parameters which have intervals associated, the lower and upper bounds (Tab. 2) were achieved with a good precision too (comparison of Tabs. 1 and 2). The last column of Tab. 3 presents the coefficient of variation, which can only be evaluated in what refers to aleatory-type UIQs and the SRQs. Between the UIQs, h is the 
variable that presents the greatest value, followed by $\mathrm{b}$, and $\mathrm{F}$ (the minor contributor). In other words, the standard dispersion of data is the greatest for the cross-section height of the beam and the lowest for the applied load. When analogous comparison is made between the SRQs, the fatigue life $\mathrm{N}$ is almost one order of magnitude greater than the stress, thus presenting the greatest dispersion.

\begin{tabular}{|c|c|c|c|c|}
\hline $\begin{array}{l}\text { UIQ/ } \\
\text { SRQ }\end{array}$ & Deterministic value & Estimated lower bound & Estimated mean & Estimated upper bound \\
\hline $\mathrm{b}$ & $\mathrm{b}^{\mathrm{D}}=33.600 \mathrm{~mm}$ & $\mathrm{~b}^{\mathrm{LB}}=33.279 \mathrm{~mm}$ & $\mu_{\mathrm{b}}=33.598 \mathrm{~mm}$ & $\mathrm{~b}^{\mathrm{UB}}=33.863 \mathrm{~mm}$ \\
\hline $\mathrm{h}$ & $\mathrm{h}^{\mathrm{D}}=60.480 \mathrm{~mm}$ & $\mathrm{~h}^{\mathrm{LB}}=60.178 \mathrm{~mm}$ & $\mu_{\mathrm{h}}=60.477 \mathrm{~mm}$ & $\mathrm{~h}^{\mathrm{UB}}=60.782 \mathrm{~mm}$ \\
\hline F & $\mathrm{F}^{\mathrm{D}}=6000.000 \mathrm{~N}$ & $\mathrm{~F}^{L B}=5984.296 \mathrm{~N}$ & $\mu_{\mathrm{F}}=5998.931 \mathrm{~N}$ & $\mathrm{FuB}^{\mathrm{UB}}=6004.135 \mathrm{~N}$ \\
\hline $\mathrm{d}$ & $\mathrm{d}^{\mathrm{D}}=2000.000 \mathrm{~mm}$ & $\mathrm{~d}^{\mathrm{LB}}=1990.001 \mathrm{~mm}$ & $\mu_{\mathrm{d}}=1999.942 \mathrm{~mm}$ & $\mathrm{~d}^{\mathrm{UB}}=2009.989 \mathrm{~mm}$ \\
\hline C & $\mathrm{C}^{\mathrm{D}}=1.862087 \times 10^{9}(\mathrm{MPa})^{\mathrm{m}}$ & $\mathrm{C}^{\mathrm{LB}}=1.852784 \times 10^{9}(\mathrm{MPa})^{\mathrm{m}}$ & $\mu_{\mathrm{C}}=1.861998 \times 10^{9}(\mathrm{MPa})^{\mathrm{m}}$ & $\mathrm{C}^{\mathrm{UB}}=1.871393 \times 10^{9}(\mathrm{MPa})^{\mathrm{m}}$ \\
\hline $\mathrm{m}$ & $\mathrm{m}^{\mathrm{D}}=3.570$ & $\mathrm{~m}^{\mathrm{LB}}=3.552$ & $\mu_{\mathrm{m}}=3.569$ & $\mathrm{~m}^{\mathrm{UB}}=3.588$ \\
\hline $\mathrm{S}_{\mathrm{MAX}}$ & $\mathrm{S}_{\mathrm{MAX}} \mathrm{D}=585.800 \mathrm{MPa}$ & $\mathrm{S}_{\mathrm{MAX}}^{\mathrm{LB}}=572.932 \mathrm{MPa}$ & $\mu_{\mathrm{S}}=585.823 \mathrm{MPa}$ & $\mathrm{S}_{\mathrm{MAX}}{ }^{\mathrm{UB}}=597.900 \mathrm{MPa}$ \\
\hline $\mathrm{N}$ & $\mathrm{ND}=3071$ cycles & $\mathrm{N}^{\mathrm{LB}}=2421$ cycles & $\mu_{\mathrm{N}}=3080$ cycles & $\mathrm{N}^{U B}=3781$ cycles \\
\hline
\end{tabular}

Table 2: Statistical parameters obtained from the simulations for both UIQs and SRQs.

\begin{tabular}{|c|c|c|c|c|c|}
\hline $\begin{array}{l}\text { UIQ/ } \\
\text { SRQ }\end{array}$ & Deterministic value & Estimated mean & $\begin{array}{c}\text { Estimated } \\
\text { standard deviation }\end{array}$ & $\begin{array}{l}\text { Relative error } \\
\left.\text { (x 10 } 10^{-3} \%\right)\end{array}$ & $\begin{array}{c}\text { Coefficient of } \\
\text { variation }\left(\mathrm{x} 10^{-3}\right)\end{array}$ \\
\hline $\mathrm{b}$ & $\mathrm{b}^{\mathrm{D}}=33.600 \mathrm{~mm}$ & $\mu_{\mathrm{b}}=33.598 \mathrm{~mm}$ & $\sigma_{\mathrm{b}}=0.0827 \mathrm{~mm}$ & $\varepsilon_{\mathrm{b}}=5.952$ & $\mathrm{COV}_{\mathrm{b}}=2.461$ \\
\hline $\mathrm{h}$ & $\mathrm{h}^{\mathrm{D}}=60.480 \mathrm{~mm}$ & $\mu_{\mathrm{h}}=60.477 \mathrm{~mm}$ & $\sigma_{\mathrm{h}}=0.174 \mathrm{~mm}$ & $\varepsilon_{\mathrm{h}}=4.960$ & $\mathrm{COV}_{\mathrm{h}}=2.877$ \\
\hline $\mathrm{F}$ & $\mathrm{FD}^{\mathrm{D}}=6000.000 \mathrm{~N}$ & $\mu_{\mathrm{F}}=5998.931 \mathrm{~N}$ & $\sigma_{\mathrm{F}}=2.329 \mathrm{~N}$ & $\varepsilon_{\mathrm{F}}=17.82$ & $\mathrm{COV}_{\mathrm{F}}=0.388$ \\
\hline d & $\mathrm{d}^{\mathrm{D}}=2000.000 \mathrm{~mm}$ & $\mu_{\mathrm{d}}=1999.942 \mathrm{~mm}$ & Not applicable & $\varepsilon_{\mathrm{d}}=2.900$ & Not applicable \\
\hline $\mathrm{C}$ & $\mathrm{C}^{\mathrm{D}}=1.862087 \times 10^{9}(\mathrm{MPa})^{\mathrm{m}}$ & $\mu_{\mathrm{C}}=1.861998 \times 10^{9}(\mathrm{MPa})^{\mathrm{m}}$ & Not applicable & $\varepsilon_{C}=4.780$ & Not applicable \\
\hline $\mathrm{m}$ & $\mathrm{m}^{\mathrm{D}}=3.570$ & $\mu_{\mathrm{m}}=3.569$ & Not applicable & $\varepsilon_{\mathrm{m}}=2.801$ & Not applicable \\
\hline $\mathrm{S}_{\mathrm{MAX}}$ & $\mathrm{S}_{\mathrm{MAX}} \mathrm{D}=585.800 \mathrm{MPa}$ & $\mu_{\mathrm{S}}=585.823 \mathrm{MPa}$ & $\sigma_{\mathrm{S}}=4.0558 \mathrm{MPa}$ & $\varepsilon_{\mathrm{S}}=0.5121$ & $\mathrm{COV}_{\mathrm{S}}=6.923$ \\
\hline $\mathrm{N}$ & $\mathrm{ND}=3071$ cycles & $\mu_{\mathrm{N}}=3080$ cycles & $\sigma_{\mathrm{N}}=197.9$ cycles & $\varepsilon_{N}=293.1$ & $\mathrm{COV}_{\mathrm{N}}=64.25$ \\
\hline
\end{tabular}

Table 3: Statistical parameters obtained from the simulations for both UIQs and SRQs.
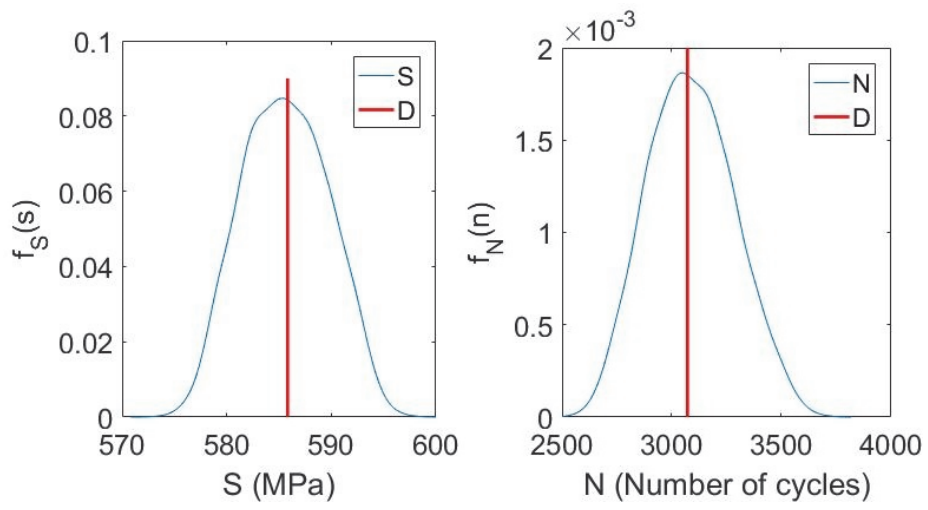

Figure 4: PDFs of SRQs and their deterministic values. 

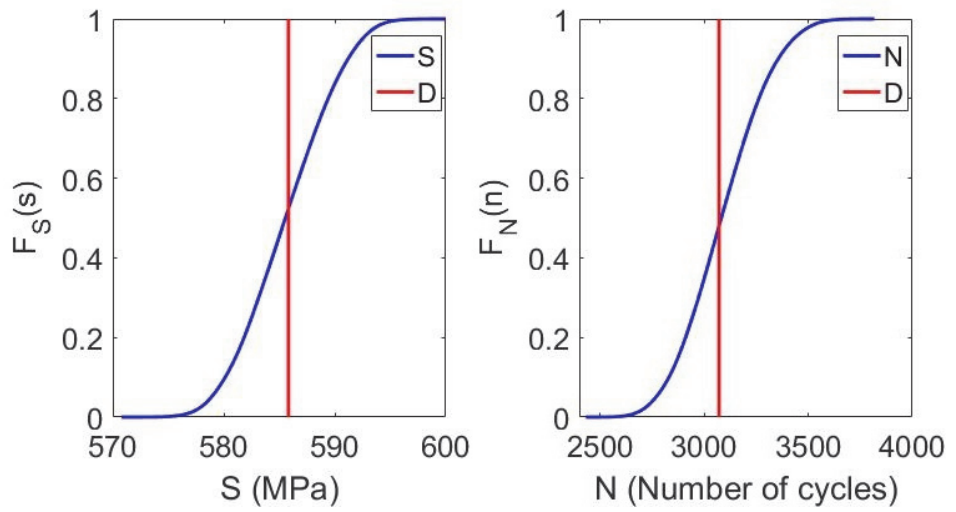

Figure 5: CDFs of SRQs and their deterministic values.

The convergence of the means of the aleatory-type UIQs and SRQs are shown in Fig. 6 and Fig. 7, respectively. The relative error of these variables are presented in Tab. 4. For example, if a relative error criteria of $0.02 \%$ is adopted for these UIQs, the minimum required number of realizations will be $n_{r}=4775$ in order to have a relative error of $0.3 \%$ in the SRQs. At $n_{r}$ $=5000$, a relative error of $5.952 \times 10^{-3} \%, 4.960 \times 10^{-3} \%$, and $17.82 \times 10^{-3} \%$ in the UIQs b, h, and F, respectively, produce relative errors of $0.5121 \times 10^{-3} \%$ and $293.1 \times 10^{-3} \%$ in the SRQs S (first level) and N (second level), respectively. This leads to the partial conclusion that the fatigue life $\mathrm{N}$ is the more restrictive parameter when the objective is to minimize the number of realizations (computational effort). This is explained by the fact that the uncertainty is propagated through two levels to achieve the results for the number of cycles; in contrast, the obtainment of stress demands just one level. It is important to note that the low $n_{r}$ for the UIQs does not account for the stabilization of the mean throughout the process of generation of realizations. Therefore, the number of realizations contained in this table accounts only for the strictly necessary to achieve the deterministic value within the error margin defined in Tab. 4. To also ensure the stabilization of the mean values obtained for all variables involved, $\mathrm{n}_{\mathrm{r}}$ was chosen to be 5000 .
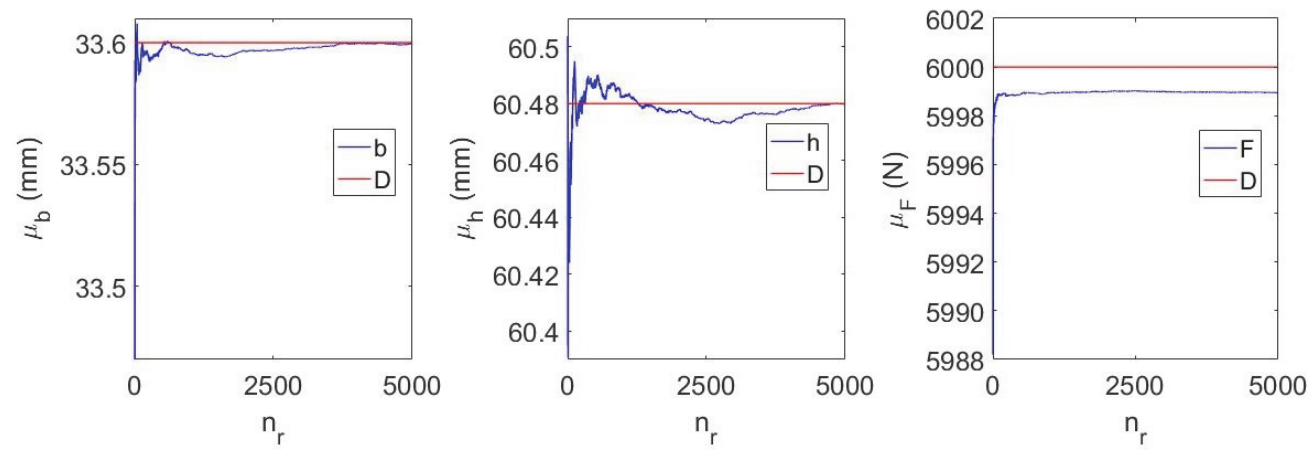

Figure 6: Convergence analysis of the means of the aleatory-type UIQs and their deterministic values.
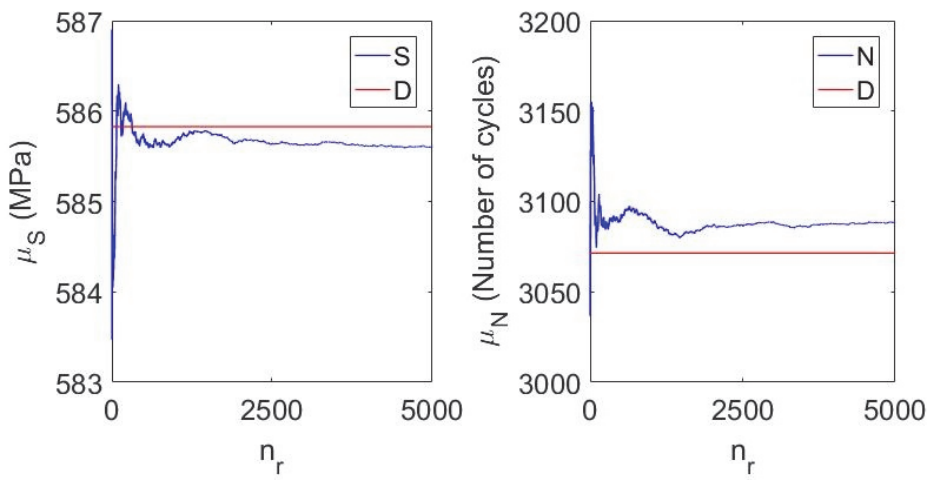

Figure 7: Convergence analysis of the means of the SRQs and their deterministic values. 


\begin{tabular}{cccccc}
\hline UIQ or SRQ & Deterministic value & $\begin{array}{c}\text { Relative error } \\
\left(\mathrm{x} 10^{-3} \%\right)\end{array}$ & $\begin{array}{c}\text { Relative error criteria } \\
(\%)\end{array}$ & $\begin{array}{c}\text { Stopping } \\
\text { realization }\end{array}$ & Estimated mean \\
$\mathrm{b}$ & $\mathrm{b}^{\mathrm{D}}=33.600 \mathrm{~mm}$ & 5.952 & 0.02 & $\mathrm{n}_{\mathrm{r}}=51$ & $\mu_{\mathrm{b}}=33.598 \mathrm{~mm}$ \\
$\mathrm{~h}$ & $\mathrm{~h}^{\mathrm{D}}=60.480 \mathrm{~mm}$ & 4.960 & 0.02 & $\mathrm{n}_{\mathrm{r}}=49$ & $\mu_{\mathrm{h}}=60.477 \mathrm{~mm}$ \\
$\mathrm{~F}$ & $\mathrm{FD}^{\mathrm{D}}=6000.000 \mathrm{~N}$ & 17.82 & 0.02 & $\mathrm{n}_{\mathrm{r}}=19$ & $\mu_{\mathrm{F}}=5998.931 \mathrm{~N}$ \\
$\mathrm{~S}_{\mathrm{MAX}}$ & $\mathrm{S}_{\mathrm{MAX}}=585.800 \mathrm{MPa}$ & 0.5121 & 0.3 & $\mathrm{n}_{\mathrm{r}}=4$ & $\mu_{\mathrm{S}}=585.823 \mathrm{MPa}$ \\
$\mathrm{N}$ & $\mathrm{N}^{\mathrm{D}}=3071$ cycles & 293.1 & 0.3 & $\mathrm{n}_{\mathrm{r}}=4775$ & $\mu_{\mathrm{N}}=3080 \mathrm{cycles}$ \\
\hline
\end{tabular}

Table 4: Statistical parameters of the obtained SRQs stress and fatigue life.

The sensitivity analyses (SAs) performed also help in the task of mapping the impact of non-deterministic parameters in terms of the required response for future actions aiming at reducing the dispersion and improving the accuracy of the SRQs. The SAs were performed via scatter plots of the SRQs related to the aleatory-type UIQs involved and by the comparison of the correlation coefficients. Fig. 9 pictures how the stress S depends on these three parameters and Fig. 10 illustrates the dependence of fatigue life $\mathrm{N}$ on these parameters. The dashed black horizontal lines correspond to the deterministic values of the SRQs and the continuous red vertical lines in these figures give the deterministic values of the UIQs. The correlation coefficients between the variables are found in Tab. 5, where the most relevant aleatory-type UIQ in these simulations is the cross-section height h of the beam for both S and N SRQs. The least influencing UIQ is the applied load F, presenting a low correlation factor. The intermediate parameter in terms of impact on the SRQs is the cross-section basis b. Independently of their magnitude of contribution to the SRQs variability, the extent to which the uncertainty is propagated, all the UIQs lose influence when the analysis is first made related to $\mathrm{S}$ and, right after to N. For example, the correlation coefficient of $\mathrm{b}$ related to $\mathrm{S}$ is $\varphi_{\mathrm{bS}}=-0.3747$ while the coefficient of $\mathrm{b}$ directly related to $\mathrm{N}$ is $\varphi_{\mathrm{bN}}=0.3048$, where the parameter b partially loses approximately $18.65 \%$ of its correlation capacity throughout the process of uncertainty propagation. Height $\mathrm{h}$ and applied $\mathrm{F}$ load lose $21.76 \%$ and $13.29 \%$, respectively.
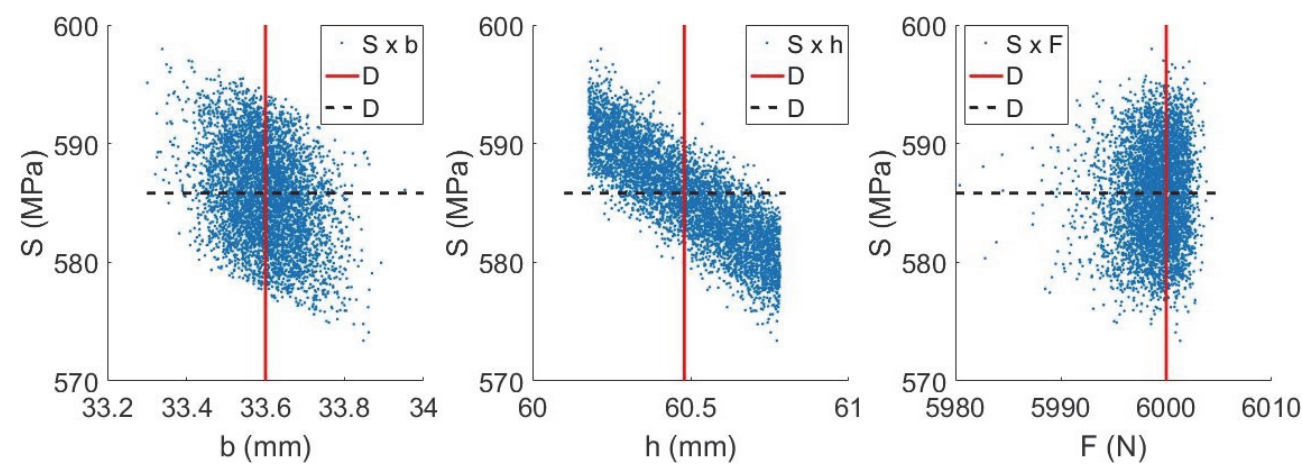

Figure 8: Sensitivity analysis of the aleatory-type UIQs related to the stress SRQ and their deterministic values.
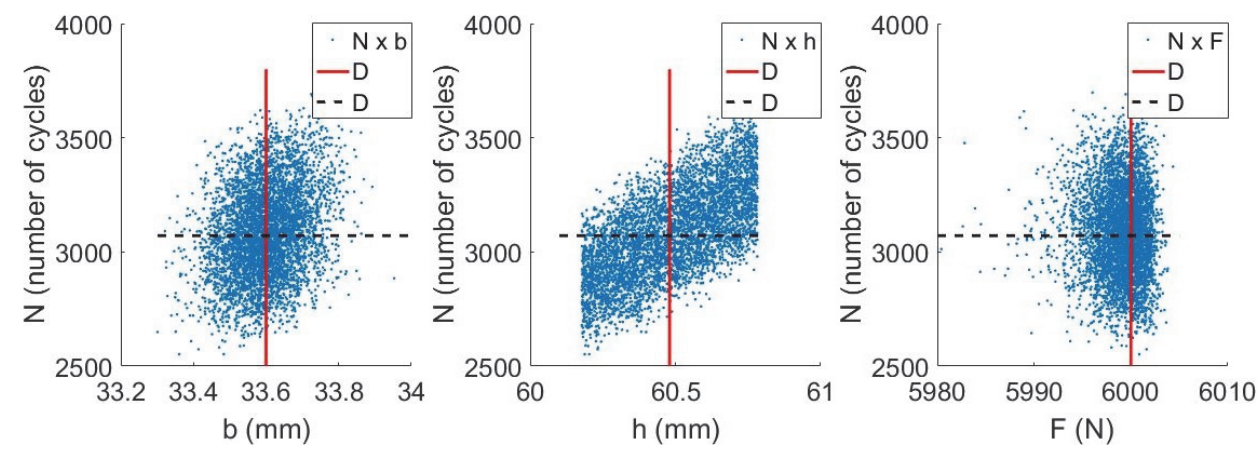

Figure 9: Sensitivity analysis of the aleatory-type UIQs related to the number of cycles SRQ and their deterministic values. 
Fig. 10 shows the distribution realizations with respect to the mentioned load condition, which covers just a little portion of the S-N curve. The correlation factor is $\varphi_{S N}=0.7922$, which demonstrates great influence of the UIQ S on the SRQ N.

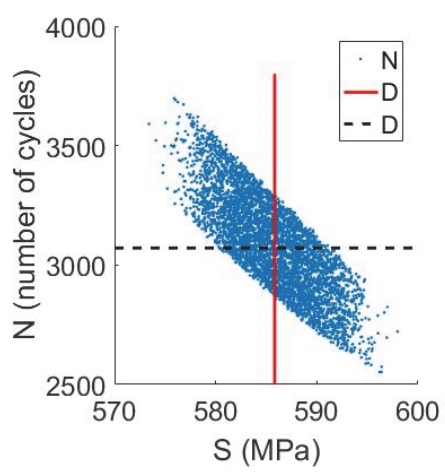

Figure 10: Sensitivity analysis of SRQ stress related to the SRQ fatigue life and their deterministic values.

\begin{tabular}{ccc}
\hline UIQ & SRQ & $\begin{array}{c}\text { Correlation } \\
\text { coefficient }\end{array}$ \\
b & S $_{\text {MAX }}$ & $\varphi_{\mathrm{bS}}=-0.3747$ \\
h & S $_{\text {MAX }}$ & $\varphi_{\mathrm{hS}}=-0.8347$ \\
F & $\mathrm{S}_{\mathrm{MAX}}$ & $\varphi_{\mathrm{FS}}=0.0790$ \\
$\mathrm{~b}$ & $\mathrm{~N}$ & $\varphi_{\mathrm{bN}}=0.3048$ \\
$\mathrm{~h}$ & $\mathrm{~N}$ & $\varphi_{\mathrm{hN}}=0.6531$ \\
$\mathrm{~F}$ & $\mathrm{~N}$ & $\varphi_{\mathrm{FN}}=-0.0685$ \\
$\mathrm{~S}_{\mathrm{MAX}}$ & $\mathrm{N}$ & $\varphi_{\mathrm{SN}}=-0.7922$ \\
\hline
\end{tabular}

Table 5: Correlation coefficients between UIQs and SRQs.

Combining the information from Tabs. 3, 4, and 5, the cross-section height h is the aleatory-type UIQ with simultaneously the greatest dispersion and the greatest impact on the stress SRQ. In the second position, the parameter b; and the last in dispersion and correlation is the applied load. It is important to observe that not always the one with the highest correlation will have the greatest dispersion.
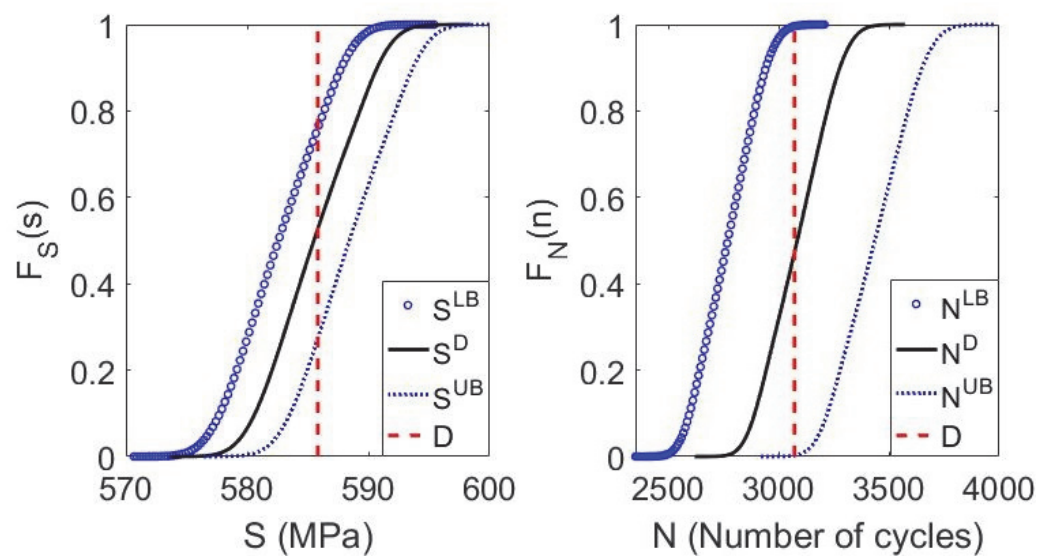

Figure 11: P-boxes of SRQs stress and number of cycles, and their deterministic values. 
In order to assess the overall contribution of the UIQs on the SRQs, but in a segregated mode, the p-boxes of both SRQs are shown in Fig. 11. The p-box indicates the set of all possible CDFs contained within design boundaries and it tries to allow the engineer to make the most adequate decisions in terms of UIQs, aiming at reducing the dispersion of the required SRQ. The first p-box illustrates the effect of the aleatory-type uncertainty from the UIQs b, h, and F, and the epistemictype due to UIQ d on the SRQ stress. In the second p-box, besides the influence of the UIQs just described, the epistemic UIQs $\mathrm{C}$ and $\mathrm{m}$ are also taken into account when assessing the effect on SRQ fatigue life. The blue curves represented by circles are the lower probabilistic boundaries of the SRQs shown on the horizontal axis. The black continuous curves are the probabilistic responses if the possibility of the deterministic values of the epistemic-type UIQs are realized. The pointed lines correspond to the upper probabilistic boundaries of the SRQs, and the vertical dashed lines are the deterministic values of the SRQs represented. Consequently, any design point within these design boundaries is theoretically possible. To reduce the variability of these results more information should be added up to the design and/or process controls should be improved.

\section{CONCLUSIONS}

7 his paper presents a bi-level hybrid uncertainty quantification scheme capable of dealing with both aleatory- and epistemic-type uncertainties in the context of a fatigue analysis. The bi-level hybrid methodology adds up the possibility of working with cases where there is no sufficient knowledge about the behavior of a variable in two distinct levels. From this perspective, the uncertain fatigue analysis is able to produce a range of possible solutions, working with limited information from the UIQs. With these capabilities attached, the proposed scheme was assessed by conducting an analysis of a clamped rectangular cross-section beam subjected to a concentrated load, which material information is extracted from experimental data available in the literature for the AISI 4130.

As this type of analysis evidenced that there is a rank of most influencing fatigue design factors (UIQs), the most effective manner to improve the referred design is to implement changes directly on the most relevant UIQs, if possible. The comparison of the results obtained via this scheme with those achieved by the deterministic analysis evidences that the first tries to reproduce the discreteness intrinsic to uncertainties from manufacturing processes, design, and service conditions. Besides that, the uncertain fatigue analysis, instead of providing a unique threshold value for the SRQs, now yields a possible working range. Depending on the risk that an engineer can take on a specific design, there will be a corresponding level of optimization achieved.

Another point to be highlighted is that the results obtained in terms of the required SRQs directly depends on the choice of the mathematical model of each UIQ. A different range of results would be obtained in the case of adding up information to the analysis performed. Moreover, the method wherewith the uncertainties are propagated through the model is determinant to the definition of possible ranges of response variables.

In a general manner, the referred findings emphasize that the behavior of the uncertain responses depends largely on the information provided as input uncertain data. Thenceforth, there is a growing need to expand the knowledge related to these types of problems in order to produce not only a safe design, but also to propose the most effective design improvements.

\section{ACKNOWLEDGEMENTS}

he author is very grateful to CEREARERM for the support under project number 01262113.

\section{REFERENCES}

[1] Campbell, F. C. (2012). Fatigue and Fracture: Understanding the Basics, Materials Park, ASM International.

[2] Echard, B., Gayton, N., and Bignonnet, A. (2014). A reliability analysis method for fatigue design, International Journal of Fatigue, 59, pp. 292-300. DOI: 10.1016/j.ijfatigue.2013.08.004.

[3] Meng, G., Feng, X., Zhou, L., and Li, F. (2016). Hybrid reliability analysis of structural fatigue life: based on Taylor expansion method, Advances in Mechanical engineering, 8(11), pp. 1-11. DOI: 10.1177/1687814016677023. 
[4] Oberkampf, W. L. and Roy, C. J. (2010). Verification and Validation in Scientific Computing, Cambridge, Cambridge University Press.

[5] Li, Y., Hu, M., and Wang, F. (2016). Fatigue life analysis based on six sigma robust optimization for pantograph collector head support, Advances in Mechanical Engineering, 8(11), pp. 1-9. DOI: 10.1177/1687814016679314.

[6] Pook, L. (2007). Metal Fatigue: Why it is, Why it matters, Dordrecht, Springer.

[7] Paolino, D. S., Tridello, A., Geng, H. S., Chiandussi, G., Rossetto, M. (2014). Duplex S-N fatigue curves: statistical distribution of the transition fatigue life, Frattura ed Integrità Strutturale, 30, pp. 417-423.

DOI: $10.3221 /$ IGF-ESIS.30.50.

[8] Shimizu, S. (2005). P-S-N/P-F-L Curve approach using three-parameter Weibull distribution for life and fatigue analysis of structural and rolling contact components, Tribology Transactions, 48, pp. 576-582. DOI: $10.1080 / 05698190500313536$.

[9] Paolino, D. S., Chiandussi, G., and Rossetto, M. (2012). A unified statistical model for S-N fatigue curves: probabilistic definition, Fatigue and Fracture of Engineering Materials and Structures, 36, pp. 187-201. DOI: $10.1111 /$ j.1460-2695.2012.01711.x.

[10] Righiniotis, T. D., Chryssanthopoulos. (2003). Probabilistic fatigue analysis under constant amplitude loading, Journal of Constructional Steel Research, 59, pp. 867-886. DOI: 10.1016/S0143-974X(03)00002-6.

[11] Kelma, S., Schaumann, P. (2015). Probabilistic fatigue analysis of jacket support structures for offshore wind turbines exemplified on tubular joints. 12th Deep Sea Offshore Wind R\&D Conference, Trondheim, Norway, 4-6 February.

[12] Su, C., Yu, S., Wang, Z., and Tayyab, Z. (2018). A time-dependent probabilistic fatigue analysis method considering stochastic loadings and strength degradation, Advances in Mechanical Engineering, 10(7), pp. 1-9. DOI: $10.1177 / 1687814018785560$.

[13] Chen, B., and Zhi, P. (2019). Fatigue strength analysis of bogie frame in consideration of parameter uncertainty, Frattura ed Integrità Strutturale, 48, pp. 385-399. DOI: 10.3221/IGF-ESIS.48.37.

[14] Endeshaw, H. B., Ekwaro-Osire, S., Alemayehu, F. M., and Dias, J. P. (2017). Evaluation of fatigue crack propagation of gears considering uncertainties in loading and material properties, Sustainability, 9, pp. 1-15.

DOI: $10.3390 /$ su9122200.

[15] Guida, M., and Penta, F. (2010). A Bayesian analysis of fatigue data, Structural Safety, 32, pp. 64-76. DOI: $10.1016 /$ j.strusafe.2009.08.001.

[16]Zhu, S.-P., Huang, H. Z., Ontiveros, V., He, L.-P., and Modarres, M. (2012). Probabilistic low cycle fatigue life prediction using an energy-based damage parameter and accounting for model uncertainty, International Journal of Damage Mechanics, 21, pp. 1128-1153. DOI: 10.1177/1056789511429836.

[17] Wang, X., Rabiei, M., Hurtado, J., Modarres, M., and Hoffman, P. (2009). A probabilistic-based airframe integrity management model, Reliability Engineering \& System Safety, 94, pp. 932-941. DOI: 10.1016/j.ress.2008.10.010.

[18] Li, M., and Wang, L. (2011). Feature fatigue analysis in product development using Bayesian networks, Expert Systems with Applications, 38, pp. 10631-10637. DOI: 10.1016/j.eswa.2011.02.126.

[19] Sofi, A., Muscolino, G., and Giunta, F. (2019). Fatigue analysis of structures with interval axial stiffness subjected to stationary stochastic excitations, Meccanica, 54, pp. 1471-1487. DOI: 10.1007/s11012-019-01022-2.

[20]Zou, L., Yang, X., Tan, J., and Sun, Y. (2017). S-N curve modeling method of aluminum alloy welded joints based on the fatigue characteristics domain, Frattura ed Integrità Strutturale, 40, pp. 137-148. DOI: 10.3221/IGF-ESIS.40.12.

[21] Weibull, W. (1961). Testing and Analysis of Results, Oxford, Pergamon Press.

[22] Boiler, A., S., o., M., E., Committee, P., V. (1995). ASME Boiler \& Pressure Vessel Code: An Internationally Recognized Code, American Society of Mechanical Engineers.

[23] Nishijima, S. (1980). Statistical analysis of small sample fatigue data, Transactions of the Japan Society of Mechanical engineers A, 46, pp. 234-245.

[24] Miner, M. A. (1945). Cumulative damage in fatigue, Journal of Applied Mechanics, 12, pp. A159-A164.

[25] Ghanem, R., Higdon, D., and Owhadi, H. (2017). Handbook of Uncertainty Quantification, Cham, Springer.

[26] Modarres, M., Kaminskiy, M., and Krivtsov, V. (1999). Engineering and Risk Analysis - A Practical Guide, New York, Marcel Dekker.

[27] Wu, Z. R., Hu, X. T., Li, Z. X., Xin, P. P., and Song, Y. D. (2017). Probabilistic fatigue life prediction methodology for notched components based on simple smooth fatigue tests, Journal of Mechanical Science and Technology, 31(1), pp. 181-188. DOI: 10.1007/s12206-016-1219-x.

[28] Morgan, M. G. and Henrion, M. (1990). Uncertainty: a Guide to Dealing with Uncertainty in Quantitative Risk and Policy Analysis, Cambridge, Cambridge University Press. 
[29] Haldar, A. and Mahadevan, S. (2000). Probability, Reliability, and Statistical Methods in Engineering Design, New York, John Wiley.

[30] Ang, A. H.-S. and Tang, W. H. (2007). Probability Concepts in Engineering: Emphasis on Applications to Civil and Environmental Engineering, New York, John Wiley.

[31] Vose, D. (2008). Risk Analysis: a Quantitative Guide, New York, Wiley.

[32] Xiao, Z., Han, X., Jiang, C., and Yang, G. (2015). An efficient uncertainty propagation method for parameterized probability boxes, Acta Mech, 227, pp.633-649. DOI: 10.1007/s00707-015-1492-2.

[33] Rahman, S., Karanki, D. R., Epiney, A., Wicaksono, D., Zerkak, O., and Dang, V. N. (2018). Deterministic sampling for propagating epistemic and aleatory uncertainty in dynamic event tree analysis, Reliability Engineering and System Safety, 175, pp. 62-78. DOI: 10.1016/j.ress.2018.03.009.

[34] Federal Aviation Administration. (2013). Metallic Materials Properties Development and Standardization (MMPDS-08), Washington, Battelle Memorial Inst. 